\section{Os partidos na tv: uma análise dos spots não-eleitorais}

Este texto encontra-se inscrito na pesquisa "Novas configurações da política na Idade Mídia", financiada pelo CNPq. Antonio Albino Canelas Rubim é o coordenador da pesquisa. Andréa Cristiana Santos é bolsista de iniciação científica na pesquisa.

\section{Antonio Albino Canelas Rubim} Professor da Faculdade de Comunicação da Universidade Federal da Bahia (UFB). Pesquisador do CNPq e Presidente da Associação Nacional dos Programas de Pós-graduação em Comunicação - COMPÓS.

Andréa Cristiana Santos

Aluna da Faculdade de Comunicação da UFB.
As MODIFICAÇÕES SÓCIOTECNOLÓGICAS OCOrridas com a "revolução das comunicações", que tem seu início em meados do século XIX, estabelece uma nova sociabilidade na contemporaneidade. O ser, o estar e o viver o mundo não serão mais possíveis apenas pela experiência vivenciada em presença, mas se realizarão cada vez mais pela "presença" midiatizada do ausente. Instaura-se uma relação de televivência - um 'viver' em tempo real a distância - possibilitada pelas contemporâneas mediações sóciotecnológicas. Enfim, a contemporaneidade emerge como complexa convergência de convivências e televivências. ${ }^{1}$

No contexto da "revolução das comunicações" o campo das mídias, autono-mizado como os demais campos sociais, emerge como esfera obrigatória de visibilidade e de notoriedade. Como afirma Adriano Duarte Rodrigues: "nele todos os restantes campos sociais se refletem como num espelho, não podendo as dimensões da prática social prescindir do seu contri-buto" ${ }^{2}$

Nesta perspectiva, a dimensão pública do espaço virtual, constituída pelas mídias, torna-se "lugar" essencial de luta pelo poder. As mídias, com seu singular poder de publicização e silenciamento, tornam-se uma esfera constituinte e constituída do fazer política. ${ }^{3}$

Os espaços de realização da política na modernidade - ruas, praças, parlamentos, palácios, etc. - são reconfigurados pela ascensão de um outro espaço virtual de realização da política a distância: a telepolítica. Rua e tela surgem como espaços complementares e tensos do fazer política na atualidade.

A televisão, neste cenário de telepolítica, ocupa um espaço privilegiado entre todas as mídias (jornais, revistas, internet, 
rádio, etc), por seu impacto audiovisual e pela amplitude de sua difusão no mundo e no Brasil. ${ }^{4}$

A política aparece na tela da televisão disseminada nos mais variados programas: noticiários, telenovelas, humorísticos, esportivos, de auditório, etc. Mas não é somente nos espaços "normais" da programação da televisão que a política se realiza. Há na programação televisiva um momento político singular, porque à margem de sua lógica habitual de funcionamento, que são os espaços assegurados por lei aos partidos políticos. A lógica produtiva inerente a esses programas não está subordinada aos interesses político-econômicos dos proprietários das emissoras de televisão, sejam eles empresas privadas ou Estado.

Mas se a enunciação do discurso político fica sujeita a uma lógica partidária, a ocupação dos espaços televisivos não se faz sem uma adequação às gramáticas/linguagens das mídias. Atualmente, os espaços televisivos partidários se apresentam sob a forma já tradicional de horário político e no novo formato de spots políticos, inserções rápidas - 30 e 60 segundos - e difusas na programação normal.

Este artigo procura compreender como o discurso político aparece configurado no formato de spots políticos. Para tal, foram escolhidos como objeto de estudo os spots veiculados durante o período não-eleitoral, entre os meses de agosto e setembro de 1997. São utilizados na análise os spots do PDT, PFL, PT, PTB, PPB e PMDB. O trabalho privilegiou o estudo de spots por sua novidade no cenário midiático brasileiro.

\section{Espaços televisivos: lógicas e gramá- ticas}

Os espaços televisivos sob o controle dos partidos representam um momento privilegiado para a realização da política na esfera midiática. Os programas partidários possibilitam retirar a construção da política do crivo de uma lógica empresarial, inseri- da na órbita da indústria cultural, ou estatal, subordinada no Brasil ao governante de plantão, e a coloca sob a lógica dos partidos políticos. ${ }^{5}$ Através dos programas e spots, os partidos podem apresentar seu ideário, suas propostas e sua visão acerca dos problemas brasileiros e internacionais sob uma lógica política própria.

Elias Gonçalves faz uma crítica à tendência das mídias em monopolizar a publicização na sociedade, pois tal postura acaba provocando uma disputa permanente pelo domínio da enunciação dos discursos. ${ }^{6}$ Os espaços televisivos partidários neste cenário apresentam-se como um meio de democratizar as relações desiguais entre as donos das organizações televisivas, o Estado e os atores políticos.

Os programas políticos podem agendar e fazer enquadramentos acerca dos temas de relevância política, inclusive, retomando discursos políticos já acionados pela mídia, sob a lógica dos partidos. Se na programação normal televisiva os mídias atuam de modo decisivo no agendamento de temas, produção de imagens sociais, na criação de atmosferas sóciopolíticas e na construção de cenários políticos, os programas partidários possibilitam, ainda que momentaneamente, retirar a construção da política da órbita desta lógica, limitando os poderes das mídias. ${ }^{7}$

Coexistem assim dois momentos distintos, ainda que desiguais, na realização da política na esfera midiática: um sob controle direto das mídias e o outro dependente da lógica dos partidos. Não se pode ignorar, entretanto, que os programas políticos devem obedecer às gramáticas/linguagens televisivas, sem as quais não podem transitar satisfatoriamente no meio.

Afonso de Albuquerque afirma que os programas políticos propõem construir uma realidade, uma versão acerca do sentido do real. Os programas telejornalísticos também são uma construção de uma determinada visão da realidade. Entretanto, os programas políticos procuram também criar uma identificação entre o telespec- 
tador e as propostas partidárias ou suas lideranças. Os programas políticos, mais do que oferecer um modelo explicativo acerca do significado da realidade, convidam o telespec-tador a se tornar um "...agente dessa realidade, modificando-a para melhor" ${ }^{8}$ No texto, o autor ignora que o convite pode também ser realizado em sentido inverso: a mera reafirmação e continuidade de uma dada realidade. Trata-se afinal de criar laços de identidade entre o telespectador, os partidos e suas lideranças, que apresentam a sua concepção própria de política e tentam conquistar o telespectador para que compartilhe da sua visão. ${ }^{9}$

Murilo Soares concebe os programas políticos como uma espécie de competição, realizada pelo acionamento de meios dramáticos e discursivos entre personagens políticos, pela avaliação e definição de um cenário, com o objetivo de fazer com que as representações sejam compartilhadas pelo telespectador, sob a forma de visões retóricas da realidade. Através dos espaços televisivos, os partidos e as personalidades políticas propõem significados para si próprio e para os outros. ${ }^{10}$

Cada partido vai ocupar os espaços televisivos com a sua visão própria de política, defendendo as suas propostas e se contrapondo às de seus adversários, com o objetivo de demonstrar que a sua visão acerca da realidade está correta ou que ele seria o melhor governo da sociedade.

\section{Conformação histórica dos horários partidários}

Historicamente, os programas políticos no Brasil consolidaram-se através de um conjunto de leis que regulamenta o acesso gratuito ao rádio e à televisão tanto dos candidatos quanto dos partidos políticos em períodos não-eleitorais. As questões centrais que norteiam a aprovação da legislação estão em torno da distribuição do tempo destinado aos partidos, das restrições às gramáticas/linguagens televisivas e do caráter de gratuidade da veiculação dos programas.

O formato de programa político televisivo predominante será dado pelo horário político (eleitoral ou não), que interrompe a programação normal em todas as redes de televisão. ${ }^{11}$ A partir de 1996, no entanto, emerge e começa a se consolidar também o spot político, como novo formato de realização da política na mídia. ${ }^{12}$ A lei 9.096/9.100 de $1^{\circ}$ de setembro de 1995 torna possível a utilização de inserções comerciais de 30 e 60 segundos paralelas ao horário eleitoral "tradicional".

Em verdade, os spots políticos apareceram no cenário político-midiático nas eleições de 1974, quando o MDB negociou com as empresas de comunicação a substituição dos programas eleitorais de 20 minutos pela veiculação de vinte spots de 30 segundos. Os spots continham discursos curtos e imagens fortes espalhados pela programação normal das emissoras. ${ }^{13}$

Em 1976, uma nova legislação eleitoral, conhecida como "lei Falcão", impõe severas restrições às gramáticas/linguagens e conteúdos dos programas políticos, que só poderiam apresentar a foto, o nome, o número e um breve currículo dos candidatos, além de informar local e dia de comício. Com isto se breca, dentre outras coisas, o desenvolvimento da experimentação inicial brasileira com os spots.

A restrição aos recursos gramaticaislingüísticos voltou a ocorrer nas eleições de 1994. Os partidos estavam proibidos de usar imagens externas, montagens e trucagens. Além disso, os programas só poderiam apresentar a imagem do candidato, impedindo a aparição de outras lideranças e personalidades. Este dispositivo de lei acabou restringindo a potência criadora da campanha eleitoral, impedindo a conjunção da realização da política em espaços geográficos - as ruas, praças, etc. - e virtuais, a tela. ${ }^{14}$

Se os espaços partidários brasileiros obedecem às normas da legislação, que são determinantes para configurar o formato, 
isto não vai ocorrer em outros países. A propaganda norte-americana, por exemplo, é totalmente diversa da brasileira. Os programas políticos são pagos, sendo coordenados por assessores publicitários que se referenciam na lógica publicitária atenta aos efeitos desejados. Devido à inexistência de uma legislação específica, não há controle do tempo, nem limitações ao uso de recursos gramaticais-lingüísticos. $\mathrm{O}$ período de veiculação e a quantidade de tempo disponíveis para a divulgação são adquiridos comercialmente junto às emissoras. Nessas condições, a propaganda política americana acabou privilegiando os spots, marca-damente publicitários, como formato específico.

Já a propaganda política na França traz algumas especificidades que são semelhantes à brasileira. A propaganda política francesa é fortemente regulamentada e sofre restrições quanto ao uso de gramáticas e à distribuição de tempo.

Os partidos possuem um tempo igual para a divulgação dos programas, sendo proibida a propaganda política paga em período eleitoral. Como os programas são proibidos de usar imagens externas, as únicas cenas possíveis são as realizadas em estúdio. Os candidatos olham diretamente para a câmera, simulando uma relação "olho no olho" com o telespectador.

Há restrição à utilização de clips musicais, que só podem ocupar a percentagem de $40 \%$ de todo o tempo da transmissão do programa.

A legislação eleitoral francesa proíbe ainda a exibição de símbolos nacionais como a execução do hino nacional e o uso da bandeira. ${ }^{15}$

Se a distribuição do tempo na televisão francesa é igual para todos os partidos, na legislação brasileira a distribuição do tempo disponível é feita conforme o tamanho da bancada no Legislativo, o que acaba provocando acordos políticos entre os partidos para aumentar o seu tempo de exibição de candidaturas na mídia.

Horário político tradicional e spots:

\section{caracterizações}

A obediência a um tempo prédeterminado pela legislação faz com que o horário político eleitoral concentre as mensagens de todos os candidatos em um único bloco. As mensagens eleitorais são seqüenciais, demandando a existência de vinhetas e de clips musicais, que separam as fronteiras internas e identificam os programas. Como são diários, os programas têm que apresentar novidades durante o decorrer da campanha eleitoral.

Já as mensagens dos spots possuem formato próprio e autonomia para poderem ser repetidas durante a programação normal. São peças curtas e independem de uma ordem seqüencial de mensagens que possibilitem a identidade do programa em meio a outras, como ocorre no horário político eleitoral.

O surgimento deste novo formato não significa, sem mais, a abolição do horário político anterior. Tudo leva a crer que vamos ter no país uma complexa e ainda não definida coexistência entre horário tradicional e spots. Este, por ser uma novidade em termos de formato de programa político no Brasil, ainda não cristalizou um modelo específico. Não se pode ignorar a herança político-midiática do horário político tradicional que já consolidou um tipo de programa político com características próprias e pode influenciar no processo de formação de um estilo próprio para o spot.

Algumas questões derivadas desta coexistência de imediato emergem: quais as relações hoje mantidas entre estes tipos de programas políticos e quais as características que os spots vêm adquirindo no país.

Afonso de Albuquerque afirma que os spots no Brasil não podem ser pensados como desvinculados das gramáticas do horário político tradicional. Este autor, inclusive, refuta a idéia de que os spots brasileiros possuam uma linguagem semelhante aos spots americanos. Na análise dos spots eleitorais da campanha de 1996, o autor encontrou nos spots semelhanças com o 
horário político eleitoral tradicional, como as mensagens de pedagogia do voto e a fala do candidato olhando diretamente para a câmara (talking head). Outra discrepância: os spots americanos privilegiam as mensagens de forte apelo emocional, com pouco conteúdo informacional, além de não fazer referência constante às questões políticas nem às legendas partidárias, ao contrário da propaganda política brasileira que é obrigada, por lei, a identificar os símbolos partidários.

Os programas políticos do período não-eleitoral assumem características próprias no seu formato e conteúdo, divergindo muitas vezes dos programas eleitorais, devido inclusive aos seus propósitos distintos. Se no período eleitoral os partidos centralmente se utilizam de estratégias como discurso de campanha, de metacampanha e de pedagogia do voto, ${ }^{16}$ cujo objetivo é "ensinar" através de jingles e clips o telespectador a votar, os programas não-eleitorais procuram acionar outras mensagens e gramáticas.

Os programas políticos do período não-eleitoral divulgam, em geral, mensagens acerca do ideário partidário, da atuação administrativa para divulgar as obras realizadas na gestão do partido, de defesa das propostas políticas em questão no Congresso, de apoio aos aliados políticos, de campanha de filiação, entre outras. As mensagens de campanha de filiação são significativas, pois os partidos tentam persuadir o telespectador a compartilhar da visão de mundo do partido e a fazer parte do processo de construção do mesmo. Pode-se dizer que é o primeiro contato com um eleitor em potencial. Deste modo, ainda que haja uma distinção entre programas eleitorais e não-eleitorais, ela não significa uma ruptura radical entre ambos.

Ao ocupar os tempos televisivos, o discurso político acaba incorporando as regras e formatações do circuito midiático, assimilando as linguagens/gramáticas televi-sivas sem as quais não poderia transitar nesse espaço. $\mathrm{O}$ modo como os partidos fazem isso, no entanto, denuncia as suas di- versas visões de mundo e da política.

\section{Análise dos spots não-eleitorais}

Cabe agora relembrar e analisar os spots veiculados no período analisado.

\section{PFL}

O Partido da Frente Liberal (PFL) veiculou nacionalmente três spots, com o mesmo tipo de mensagem e de recursos audiovisuais. O cenário visual do spot prevalece nos três, com mudanças apenas nos personagens. $\mathrm{O}$ enfoque das mensagens, que é a associação entre um determinado elemento do cenário sociopolítico com a imagem do partido, permanece o mesmo.

$\mathrm{O}$ spot do PFL acionou mensagens curtas, com referência à associação da moeda - o Real - com a imagem do partido. $\mathrm{O}$ spot procura criar uma identidade como comprova a vinheta: PFL é Real.

As mensagens acionadas, muito mais do que se mostrar favorável à moeda, afirmam que o discurso a favor do Real também é o do partido. Se nas eleições de 94 o único partido a associar-se, diretamente, à manutenção do Real, era o PSDB, o spot do PFL almeja criar identificação com o mesmo e a utilizá-lo como estratégia política, como demonstram as falas:

Fala de Antônio Neves Neto, empresário:

- O Real está tocando, eu acho, o Brasil prafrente.

Fala de Marilda Araújo, doméstica:

- Eu queria que ficasse assim, até meus filhos crescessem, e eu bem velhinha (risos).

Essa associação entre PFL e o Real é ressaltada nos recursos audiovisuais que são acionados. No vídeo aparece a imagem da bandeira do Brasil com a montagem de desenhos de moedas de um Real, que serve de pano de fundo para todos os cenários do spot. Detalhe: a imagem do círculo azul com as estrelas da bandeira fica no lado 
esquerdo do vídeo, do lado direito as cores verde e amarelo, que deixam mais visíveis as moedas. As imagens de populares são inseridas através de uma janela que é sobreposta à de pano de fundo.

O spot faz uma apropriação da estabilização da economia como um símbolo nacional, ao utilizar-se da imagem da bandeira envolvida pelas moedas. O PFL coloca-se a favor do Real e, implicitamente, contrapõe-se aos adversários do mesmo (oposição).

A utilização da vinheta "PFL é Real", com as cores azul, verde e amarelo, reforça ainda mais essa apropriação. O símbolo partidário passa a ser o Real, uma clara identificação entre moeda/estabilidade, nacionalidade e PFL. O uso de cenários comuns, casa, lojas e ruas, cria um clima de espontaneidade de conotação popular, ressaltando a aceitação da moeda por todos. $\mathrm{O}$ recurso de falas de populares, uma das gramáticas mais utilizadas no horário político eleitoral, procura dar maior autenticidade ao spot.

\section{PT}

O Partido dos Trabalhadores divulgou dois spots com o uso de gramáticas televisivas diferentes. A estratégia usada pelo partido, no entanto, possui o mesmo objetivo: a construção de imagem do partido.

O primeiro spot do PT relaciona a atuação do partido com os últimos acontecimentos da história política do país. O spot vai apresentar algumas particularidades em relação aos recursos audiovisuais. O partido privilegia o áudio sem apelar para a voz em off, que só aparece nos últimos minutos do spot. As imagens são acompanhadas por um som instrumental, que é fundamental para dar identidade ao spot.

O cenário é um ringue de boxe. $\mathrm{O}$ personagem, pugilista, começa a aplicar golpes, o som da batida aumenta e a câmera corta para uma outra imagem: palavra escrita:

(1) COLLOR-PC, surge em um pano de fundo preto.

Repete-se a imagem do pugilista, sobe o som e aparece a frase:

(2) ANÕES DO ORÇAMENTO. Volta a câmera para o boxeador, depois o som, e as palavras,

(3) BANCOS - PROER... ;

(4) PRECATÓRIOS - MALUF... ;

A última frase que surge no vídeo é:

(5) REELEIÇÃO DE FHC - COMPRA DE DEPUTADOS.

É importante observar como o spot aciona as mensagens políticas, o uso de imagens e do som. A gramática do spot não traz semelhanças com os recursos audiovisuais usados no horário político, podendo dizer que tem características da linguagem publicitária como demonstra o som forte do golpe do boxeador, que funciona como assinatura para o programa.

As mensagens políticas são simbólicas, não apelam para a retórica verbal nem para o recurso da voz em off. Embora as gramáticas sejam típicas de uma peça publicitária, a mensagem possui toda uma carga simbólica do mundo da política. O teles-pectador vai entender a mensagem, recorrendo ao repertório lingüístico-cultural que possui sobre os últimos acontecimentos que ocorreram no campo político. Criado esse cenário, o spot procura associar a imagem do partido à transparência de ações políticas, como demonstra a última imagem do spot. O boxeador está saindo do ringue, e emerge a voz em off:

- Partido dos Trabalhadores, há dezessete anos batendo duro na corrupção.

Ao final do spot, a vinheta:

PT - o mais sério e honesto do Brasil.

O segundo spot do PT inova ainda mais na utilização das gramáticas audiovisuais, ao usar desenhos infantis simulando uma história em quadrinhos televisionada.

Formato e conteúdo político estão integrados, não ocorrendo uma quebra de sentido na passagem das imagens e o texto em off.

O spot procura fazer enquadramentos 
específicos sob a questão política:

\section{ÁUDIO}

Voz de criança (off): Meu pai falou que está uma fera com o Fernando Henrique. Votou nele, porque ia melhorar a educação, a saúde, o emprego, a agricultura, a segurança. Agora, olha aí! Na saúde, só tem epidemia. É sarampo pra cá. É dengue pra lá, fora os mortos da hemodiálise. E, os pequeninos vão ficar sem pré-escola. E quem paga está roubado. Emprego! Pô, nem toca! A firma fechou e o meu pai está desempregado. No campo só tem desemprego, e não deixa os sem-terra pegar a terra pra trabalhar. No mais, a gente só vê tiro e morte. E, até polícia em greve. Meu pai disse que tem de mudar, e quem está certo é o Partido dos Trabalhadores.

Vinheta: PT - oposição a FHC.

\section{VÍDEO}

(1) Desenho infantil de um homem e uma mulher. Detalhe: a boca do homem está pra baixo;

(2) primeiro plano, imagem do pai;

(3) mão espalmada com a sigla FHC no centro. Palavras educação, saúde, emprego sobrepostas à imagem da mão;

(4) hospital fechado;

(5) câmera movimenta-se de baixo para cima, fechando com close de um menino com manchas vermelhas no rosto;

(6) close de uma mulher com manchas no rosto. Movimento de câmera da direita para esquerda, surge um mosquito que se sobrepõe à imagem;

(7) homem em uma maca de hospital. Imagem sai do foco. Movimento da esquerda para direita da câmera, a maca retorna à tela;

(8) crianças em frente a uma escola; close nas crianças;

(9) homem, à esquerda do vídeo, com as mãos abertas cheias de dinheiro;

(10) close nas mãos;

(11) palavra emprego escrito em azul;

(12) desenho de uma fábrica; close na placa: fechado, em vermelho;

(13) primeiro plano, homem com roupas de fábrica; close, no rosto;

(14) trabalhador e uma plantação, lados opostos do vídeo;

(15) primeiro plano, rapaz com enxada e saco vazio;

(16) acampamento sem-terra, crianças, homem e mulher. Movimento da esquerda para a direita, retorna imagem de crianças, em primeiro plano;

(17) homem com um revólver. Aumento no ângulo da câmera, surge uma TV;

(18) soldado;

(19) criança brincando com revólver, na TV;

(20) policial de costas para um homem com os braços levantados; dos;

(21) close no policial de braços cruza-

(22) volta o desenho do pai referido em (1). O desenho da boca é alterado, agora com o formato pra cima. Surge, ao lado da figura do pai, uma estrela do PT.

O caráter inovador ressaltado está no efeito estético produzido pelas imagens imóveis dos desenhos, característicos do formato livro, revistas, jornais. Sabendo que o veículo televisivo é caracterizado por imagens móveis, uma das problemáticas seria adaptar as imagens imóveis ao meio televisivo. Através de deslocamentos da câmera que são visualizados pelo telespec-tador, as imagens imóveis ganham mobilidade, como ocorre na da maca de hospital que, provisoriamente, sai do foco, para retornar logo em seguida. A sucessão rápidas dos quadros dos desenhos também impõe mobilidade.

A voz da criança, ao invés de conferir a impessoalidade característica da voz em off, confere pessoalidade com as entonações e as gírias infantis. Os elementos visuais dos desenhos, cores e a voz infantil impuseram um clima lúdico, que consegue se integrar com o discurso político das mensagens. Estas possuem um teor crítico, mas a linguagem é sutil e não apela para um tom agressivo. 
Ao contar a história do "pai que está uma fera" com o FHC, a criança revela a falta de compromisso do presidente com as promessas de campanha. Desmontando, uma a uma, as promessas, o spot mostra o caos instalado: epidemias, desemprego....

A política aparece singularizada, rejeitando o discurso genérico oposicionista a FHC. O partido procura, mais do que conquistar um voto dos descontentes com FHC, resgatar a mística petista do lema "sem medo de ser feliz", como demostra a frase: "meu pai disse que tem de mudar e quem está certo é o Partido dos Trabalhadores". Ao lado da estrela, a imagem do pai rindo.

Ao levar imagens imóveis, a estrutura de uma história em quadrinhos e a utilização de mensagens políticas singulares em detrimento de um discurso genérico, o spot reconfigura as gramáticas televisivas e demonstra um desejo de melhor compreender o meio e inovar.

Por outro lado, o enquadramento das questões políticas contrapõem-se à publicidade oficial do atual governo.

Os spots do PT apresentam características diferentes quanto à utilização dos recursos audiovisuais.

$\mathrm{O}$ enfoque dado às mensagens é similar nos dois spots, e tem como objetivo produzir uma imagem de partido de oposição ético e comprometido com as questões sociais.

\section{PTB}

As gramáticas televisivas utilizadas pelo Partido Trabalhista Brasileiro têm um tom mais conservador.

A propaganda do PTB trata de difundir suas idéias políticas e convidar o telespectador a se filiar ao partido. Foram veiculados quatro spots, com referências às conquistas sociais, ao passado do partido e as suas propostas atuais. Um dos spots tem a seguinte formatação:

\section{ÁUDIO}

(1) Este é o Antônio, aos 16 anos em seu primeiro emprego;

(2) aqui construindo a sua casa com as suas horas extras e o fundo de garantia;

(3) olha só ele e a família no final da semana, graças à jornada de 44 horas semanais;

(4) hum! Férias;

(5) e aqui o Antonio em seu negócio, que ele montou com aviso prévio e indenização, que recebeu de seu antigo emprego;

(6) onde tem gente trabalhando tem PTB.

\section{VÍDEO}

(1) Imagem de uma sala de aula, porta- retratos em cima da mesa. Aparece escrito no vídeo: carteira de trabalho;

(2) foto de construção da casa. Aparece a palavra escrita: $50 \%$ a mais nas horas extras;

(3) foto da família na praia. Texto: 44 horas semanais... ;

(6) volta a imagem inicial.

Vinheta: Conquistas do PTB.

O uso de recursos audiovisuais é simples, com predomínio de imagens fotográficas, uma vez que o cenário é composto por porta-retratos. $\mathrm{O}$ uso da vinheta é significativo para identificar o objetivo do partido, como comprova: Conquistas do PTB .

O partido faz uma apologia do passado do partido, através das conquistas sociais asseguradas aos trabalhadores. No entanto, as mensagens que referenciam os direitos trabalhistas aparecem sob certa lógica da política neoliberal atual. As mensagens apelam para os benefícios da carteira assinada, da possibilidade de se retirar o dinheiro do FGTS e o trabalhador se tornar um pequeno empresário, um autônomo.

Nos demais spots do PTB aparece a defesa da reforma tributária, da desregu-lamentação da economia e da reforma agrária e novas referências ao pai do partido, Getúlio Vargas, lembrado através da reprodução da carta testamento. Neste spot, há o desejo de reforçar uma identidade entre Getúlio 
Vargas e o partido, como demonstra a vinheta: Este é o PTB.

\section{PDT e PMDB}

Os partidos vão usar os espaços televisivos de modo semelhante, com o predomínio de imagens em estúdio. As mensagens políticas que foram veiculadas no spot do PMDB procuravam resgatar o passado do partido, como o responsável pela consolidação da democracia no país. Apresentou a opinião de vários parlamentares, como José Sarney e Jarder Barbalho, sobre a possibilidade do partido apresentar um candidato nas próximas eleições. As mensagens não são eleitorais e têm como objetivo mobilizar a militância.

O spot do PDT vai acionar mensagens políticas, a fim de convidar o telespectador a se filiar ao partido. Para isso se utiliza de imagens de estúdio, do presumível carisma e do discurso político de Leonel Brizola. $\mathrm{O}$ spot publiciza a imagem de um líder partidário e coloca em cena questões políticas, como comprova a fala:

- Isso não é apenas uma crítica. Veja como eu tenho razão. Qual é o setor da vida brasileira, que está bem sob esse governo? A rigor nenhum. Só o dos bancos estrangeiros, que estão aí comprando tudo. Vamos nos unir para dizer não, um não a esse governo.

A vinheta do spot é um convite ao telespectador para que se filie ao partido. O spot aciona gramáticas típicas do horário político, como a imagem de um lider político falando de frente para câmara em estúdio.

A análise dos spots do PDT e PMDB demonstram que os partidos privilegiam a retórica verbal e restringem a utilização de imagens externas nos programas. Os spots, em termos de imagens, são pobres e herdeiros diretos do horário político eleitoral.

PPB
O Partido Progressista Brasileiro divulgou três spots. Sua estratégia comum é a centralização do discurso na imagem de Paulo Maluf. O uso de cenários e recursos audiovisuais é específico de cada spot.

\section{ÁUDIO}

Voz de um homem (off):

(1) Mais uma vez, a história se repete. Mais uma vez, seus adversários se juntam, se armam e partem para o ataque. Sempre com mentiras e acusações sem provas. E sempre antes das eleições. Assim tem sido a vida de Paulo Maluf, um político sério e polêmico, de posições firmes e corajosas. Ninguém consegue ser indiferente: ou se é contra ou se é a favor;

(2) graças a sua enorme capacidade de fazer obras e de encontrar soluções para os mais complicados problemas, Paulo Maluf é querido e respeitado pelo povo. Talvez seja por isso, exatamente por isso, que ele desperte tanta inveja em seus adversários.

\section{VÍDEO}

(1) Imagem de um galpão; foco da câmera se aproxima de um alvo, com a foto de Maluf no centro; aparece um rifle; plano geral do alvo; imagem do rifle sendo engatilhado; close em um revólver; homem, na penumbra, atira; panorâmica do alvo, a bala não acerta o centro/foto de Maluf. Tiros... . Uma cápsula cai no chão, close em sapatos pretos, primeiro plano do alvo, nenhuma das balas atingiram o centro; câmera aproxima-se do alvo, close na foto de Maluf; aparece o texto;

(2) escrito sobreposto à foto de Maluf;

(3) homem com os pés em um jornal; close na manchete jornalística: Maluf lidera todas as pesquisas. Covas está em terceiro. PT em último.

A importância deste spot do PPB deve-se aos recursos audiovisuais empregados e, principalmente, a sua opção pela personalização do líder. O spot procura apresentar uma imagem favorável de Paulo 
Maluf e busca desqualificar os seus adversários políticos. Maluf é tido como a personificação da imagem do homem público perseguido pelos seus adversários.

É importante observar o contexto em que está inserido esse spot. Com o escândalo dos precatórios na administração de Celso Pitta e irregularidades na compra de frangos na sua administração, a imagem de Maluf apareceu desfavoravelmente nas mídias. Maluf, espontaneamente, exilou-se do espaço virtual. Não realizou pronunciamentos nos canais televisivos nem declarações à mídia impressa, durante a avalanche de denúncias que o envolviam direta ou indiretamente. Após os escândalos deixarem de ser acontecimentos jornalísticos e a ter repercussões políticas, o retorno. A partir desse momento inicia-se uma campanha de marketing político.

O spot procura desqualificar os adversários de Paulo Maluf, sugerindo que todas as denúncias não passam de uma conspiração eleitoreira. A manchete jornalística - Maluf lidera todas as pesquisas. Covas está em terceiro. PT em último - aparece para dar legitimidade ao discurso do spot.

Em relação aos recursos audiovisuais, é predominante a referência a uma linguagem publicitária.

Tais como a presença de elementos simbólicos como rifle e o revólver, apontado pelos dois adversários do alvo/Maluf.

A construção do cenário em um galpão traz referência simbólica ao clima de conspiração.

O spot descarta mensagens políticopartidárias, visando exclusivamente melhorar a imagem de uma personalidade política, que se sobrepõe ao partido.

Esta estratégia se mantém, inclusive com o uso de gramáticas televisivas similares, nos outros spots, cujo eixo é a ação administrativa de Maluf, na sua gestão na Prefeitura de São Paulo, a exemplo do Projeto Cingapura.

A análise deste último spot é elu-cidativa:

\section{ÁUDIO}

(1) Quando ele criou o Projeto Cingapura e afirmou que estava começando a resolver o problema das favelas de São Paulo, muita gente foi contra. Afirmavam que o Projeto Cingapura era um projeto absurdo, inviável e que não daria certo.

Voz em off:

- Quatro anos depois, o Cingapura é o maior projeto social do país e já está presente em 42 favelas de São Paulo, beneficiando 85 mil pessoas. É por isso que por onde ele passa, cada vez mais se ouve o refrão: AH! Eu Tô Maluf.

\section{VÍDEO}

(1) Imagem fora de foco, aparece uma imagem azul. Mistura de cores na tela. Aparece o texto acima (1) escrito sob o pano de fundo das imagens fora de foco;

(2) a imagem está com foco, aparece uma série de conjuntos habitacionais, acompanhados por um fundo musical.

A vinheta é a imagem de Maluf. Maluf.

Vinheta: foto de Maluf. AH! Eu Tô

A utilização da imagem difusa e das cores que são espalhadas na interface do vídeo conseguem produzir um bom efeito estético para acompanhar o áudio e o texto escrito. O uso de cores substitui a tela monocromática, recurso muito utilizado quando se deseja usar imagens com texto escrito.

As mensagens procuram apelar para a produção/reforço de uma imagem de administrador competente.

Em termos de imagens e mensagens, os spots sobre o Projeto Cingapura e sobre a segurança são semelhantes, por isso a escolha por apenas um programa para ser exemplificado.

As mensagens são comuns e pretendem ressaltar realizações administrativas.

O ponto comum aos três spots é o objetivo de publicizar uma imagem favorável de Maluf como líder político e administrador público.

\section{Conclusões preliminares}


A análise destes específicos espaços televisivos sob o controle dos partidos políticos - os spots - evidenciam, de imediato, que no caso brasileiro eles ainda não se formatam em um modelo específico e unificado, como aconteceu nos Estados Unidos. Este texto corrobora a afirmação do estudo de Afonso de Albuquerque acerca da nãoamericanização dos spots brasileiros. Em 1997, eles não tinham assimilado uma lógica produtiva nitidamente oriunda da publicidade comercial. Como foi demonstrado, o horário político tradicional e outras alternativas produtivas continuavam tendo forte incidência na produção dos spots no Brasil.

Esta diversidade de modelos não se explica somente pela reduzida história brasileira dos spots e pelas tradições próprias da comunicação política no país. Apesar de concordar com a tese de Gabriel Priolli, que os partidos políticos brasileiros - com exceção de Paulo Maluf - não têm uma compreensão e uma intervenção político-midiática estratégicas, ${ }^{17}$ pode-se propor que a diversidade de formatos dos spots depende também das intencionalidades conjunturais que orientam o uso destes curtos espaços televisivos. Obviamente esta concepção incidental deprecia fortemente a poten-cialidade da atividade político-midiática dos partidos. Deste modo, a diversidade dos spots pode ser remetida a uma análise teleológica que busque compreender as finalidades e intencionalidades inscritas nos spots.

Se o intervalo eleitoral se caracteriza como tempo de escolha pública de governantes e programas de governo, o período não-eleitoral configura-se como momento possível de exercício do poder de governar. Possível porque marcado por um outro tipo de disputa - não imediatamente eleitoral - em torno da governabilidade. Isto é, da capacidade e da legitimidade do governo de viabilizar seu programa e da(s) oposição(ões) de interferir ou até mesmo de impedir os atos e as propostas do governo. Tal disputa acontece sempre em um campo de forças, político e variável conjunturalmente. Este ambiente não-eleitoral faz da política privilegiadamente um momento de acúmulo de capital e de legitimidade políticos - diferencial importante para os tempos eleitorais -, ancorado na disputa imediata acerca de temas conjunturais, em geral decorrentes de atos do governo, ou em disputas de mais longo prazo em torno da imagem pública do partido e suas principais lideranças.

Os spots analisados podem ser localizados nestes dois tipos de disputas. Alguns spots representam tentativas de intervir e/ou deslegitimar atitudes de governo, interferindo assim sobre a governabilidade. O criativo spot, em formato de desenho animado, do PT é exemplar nesta perspectiva. Mas majoritariamente os spots estudados sugerem uma preocupação com a imagem pública do partido e/ou de suas lideranças.

Esta atenção com a imagem pública consubstancia-se nos spots através da tentativa de realizar um conjunto de associações. Diversos elementos significantes e simbologias são acionados na produção ou reafirmação destas imagens públicas nos spots.

Vários partidos recorrem a sua história (PT, PTB e PMDB), aos emblemas da nação (PDT, PFL), à preocupação como questões sociais (PTB, PT), à estabilidade social (PFL), à oposição ao governo (PT, PDT) e às personalidades políticas (PTB, PDT e PPB).

Ao qualificar sua história, os partidos, entretanto, a associam a valores distintos: retorno à democracia (PMDB), conquista de direitos sociais (PTB) e comportamento ético na política (PT).

Do mesmo modo, a associação perso-nalista do partido também se realiza de modo diferenciado: o PTB reivindica o legado de Getúlio Vargas, o PDT afirma sua identidade na liderança de Leonel Brizola e o PPB praticamente se dilui na figura de Paulo Maluf.

Aliás, os spots do PPB são exemplares como peças de produção de imagem pública, ao defender e qualificar Maluf e como submissão plena de um partido a uma personalização da política. Nos spots do PPB, mais que em qualquer outro, a política bra- 
sileira se afirma como política de personalidades e não de partidos.

Outra constatação preocupante derivada da análise dos spots políticos não-eleitorais é a quase inexistência neles de algum debate temático ou programático e alguma proposta alternativa ao realizado pelo governo, o que pode significar certa paralisia em um contexto de modificações avas-saladoras vivenciadas pela sociedade brasileira naqueles momentos, a exemplo das reformas e das privatizações engendradas por FHC.

Tal preocupação pode ser talvez atenuada pela constatação, ainda não demonstrada, que os spots são por demais compactos para realizar quaisquer daquelas exigências. Retorna-se assim a questão ainda aberta no Brasil do modelo que os spots irão privilegiar no país .

\section{Notas}

1 RUBIM, Antonio Albino Canelas. "Sociabilidade, comunicação e política contemporâneas: subsídios para uma alternativa teórica". In: Textos de Comunicação e Cultura. Salvador, (27) 3-23, primeiro semestre de 1992, p.6.

2 RODRIGUES, Adriano Duarte. "A constituição do espaço público moderno". In: Estratégias da Comunicação. Lisboa: Presença, 1990, p.42.

3 RUBIM, Antonio Albino Canelas. "A comunicação midiática e as novas configurações da política na contemporaneidade". Salvador, 1996 (texto inédito).

4 Por exemplo: dados coletados pelo IBGE em 1993 e divulgados em 1996 indicam que cerca de 76\% dos domicílios brasileiros possuíam pelo menos um aparelho de televisão.

5 RUBIM, Antonio Albino Canelas. "Comunicação, espaço público e eleições presidenciais". In: Comunicação \& Polititca. São Paulo, 9 (2/3/4) : 7-21, 1980, p.16.

6 GONÇALVES, Elias M. "A política de proveta no horário político". In: RUBIM, Antonio Albino Canelas (org.), Idade Mídia. Salvador: Edufba, 1995, p.157.
7 Sobre o poder dos mídias no agendamento de temas, produções de imagens e construção de cenários, ver RUBIM, Antonio Albino Canelas. "Mídia e política: transmissões de poder". In: MATOS, Heloisa (org), Mídia, eleições e democracia. São Paulo: Scritta, 1994.

8 ALBUQUERQUE, Afonso. "Autoridade/identidade: a construção da imagem pública de Collor e Lula na campanha de 1989". In: PINTO, MIlton José e NETO, Antonio Fausto (orgs.), Mídia \& Cultura. Rio de Janeiro: Diadorim, 1997, p. 152-153.

9 Idem, ibidem. p.154.

10 SOARES, Murilo César. "Os significados do voto". In: FAUSTO NETO, Antônio e PINTO, Milton (orgs), Mídia \& Cultura. Rio de Janeiro: Diadorim, 1997, p. 75.

11 LIMA, Venício. "Propaganda política no rádio e na televisão". In: MATOS, Heloísa (org.), Mídia, eleições e democracia. São Paulo: Scritta, 1994, p. 191.

12 Em 1993, foram utilizados os spots políticos para a propaganda destinada ao plebiscito sobre sistema e regime de governo. Ver MIGUEL, Luís Felipe. "Sentidos do passado: nação e história na campanha eletrônica para o plebiscito de 21 de abril". In: Comunicação \& Política. V III, no. 2, maio-agosto 1996.

13 ALBUQUERQUE, Afonso. "Os spots políticos: americanização da propaganda política brasileira?". Texto apresentado por ocasião do XXI Encontro Anual da ANPOCS, Caxambú/MG, 1997.

14 RUBIM, Antonio Albino Canelas. "Mídia, política e eleições brasileiras de 1989 e 1994". In: BRAGA, José Luiz; PORTO, Sérgio; e FAUSTO NETO, Antonio (orgs.), A encenação dos sentidos: mídia, cultura e política. Rio de Janeiro: Diadorim, 1995.

15 ALBUQUERQUE, Afonso. "Política versus televisão: 0 horário gratuito na campanha presidencial de 1994". In: Comunicação \& Política. Rio de Janeiro, I, (3), abril /junho, 1995, p. 50-51.

16 Ver ALBUQUERQUE, Afonso. "As gramáticas do horário político-eleitoral". In: FAUSTO NETO, Antônio e PINTO, Milton José (orgs.), 0 indivíduo e as mídias. Rio de Janeiro: 
Diadorim, 1995, p.65-97.

17 Ver PRIOLLI, Gabriel. "A propaganda disfarçada". In: Caros Amigos, São Paulo, maio de 1997, número 2, p.34. Diz 0 autor: "Na quase totalidade dos casos, 0 generoso tempo gratuito da tv e do rádio é mal utilizado pelos partidos. Alguns nem chegam a usá-lo integralmente. Creio que nenhum, com a possível exceção do PPB de Paulo Maluf, planeja essa mídia de forma global, integrada...".

\section{Referências}

ALBUQUERQUE, Afonso. "Política versus televisão: o horário gratuito na campanha presidencial de 1994". In: Comunicação \& Política. Rio de Janeiro, I (3), abril /junho, 1995.

ALBUQUERQUE, Afonso. "O horário gratuito de propaganda eleitoral os spots políticos: particularidades do audiovisual brasileiro". In: BRAGA, José L. (org.), A Encenação dos Sentidos: mídia, cultura e política. Rio de Janeiro: Diadorim, 1995.

ALBUQUERQUE, Afonso. "As gramáticas do horário eleitoral gratuito de propaganda eleitoral: observações preliminares". In: FAUSTO NETO, Antônio, e PINTO, Milton José (orgs), 0 indivíduo e as mídias. Rio de Janeiro: Diadorim, 1996.

ALBUQUERQUE, Afonso. "Autoridade/identidade: a construção da imagem pública de Collor e Lula na campanha de 1989". In: FAUSTO NETO, Antônio, e PINTO, Milton José (orgs). Mídia \& Cultura. Rio de Janeiro: Diadorim, 1997.

ALBUQUERQUE, Afonso. "Os spots políticos: americanização da propaganda política brasileira?" Texto apresentado por ocasião do XXI Encontro Anual da ANPOCS, Caxambú/ MG, 1997.

GENRO FILHO, Adelmo. 0 segredo da pirâmide. Para uma teoria marxista do jornalismo. Porto Alegre: Ortiz, 1982 (segunda edição).

GONÇALVES, Elias M. "A política de proveta no horário político". In: RUBIM, Antonio Albino Canelas (org.), Idade Mídia. Salvador: Edufba, 1995.

JOBIM, Nelson e, PORTO, Walter. Legislação eleitoral no Brasil do século XVI a nossos dias. Brasília, Secretaria de Documentação e Informação do Senado Federal. Vol. II, III. 1996.
LEI ELEITORAL № 9.504, DE 30 DE SETEMBRO DE 1997. Brasília, Senado Federal. 1997.

LIMA, Venício. "Propaganda política no rádio e na televisão". In: MATOS, Heloísa (org.), Mídia, eleições e democracia. São Paulo: Scritta, 1994.

LIMA, Venício. "Os Mídias e a Política". (Texto inédito).

MIGUEL, Luís Felipe. "Sentidos do passado: nação e história na campanha eletrônica para o plebiscito de 21 de abril". In: Comunicação \& Política. Rio de Janeiro, VIII, nำ2, maioagosto 1996.

PRIOLLI, Gabriel. "A propaganda disfarçada". In: Caros Amigos. São Paulo, maio de 1997.

RODRIGUES, Adriano Duarte. Estratégias da Comunicação. Lisboa: Presença, 1990.

RUBIM, Antonio Albino Canelas. "Comunicação, política e sociabilidade contemporâneas". In: RUBIM, Antônio Albino Canelas (org.), Idade Mídia. Salvador: Edufba, 1995.

RUBIM, Antonio Albino Canelas. "Mídia e política: transmissões de poder". In: MATOS, Heloísa (org.), Mídia, eleições e democracia. São Paulo: Scritta, 1994.

RUBIM, Antonio Albino Canelas. "Mídia, política e eleições brasileiras de 1989 e 1994". In: BRAGA, José Luiz; PORTO, Sérgio Dayrell; e FAUSTO NETO, Antônio (orgs.), A encenação dos sentidos: mídia, cultura e política. Rio de Janeiro: Diadorim, 1995.

RUBIM, Antônio Albino Canelas. "A comunicação midiática e as novas configurações da política na contemporaneidade". Texto Inédito. Salvador . 1996.

SOARES, Murilo César. "Os significados do voto". In: FAUSTO NETO, Antônio e PINTO, Milton (orgs), Mídia \& Cultura. Rio de Janeiro: Diadorim, 1997.

VENTURI, Gustavo. "Continuidade Administrativa". In: Teoria $\mathcal{E}$ Debate, São Paulo, no 33, novembro e dezembro de 1996 e janeiro de 1997. 